J. Lake Sci. (湖泊科学) , 2019, 31(6): 1559-1569

DOI 10. 18307/2019. 0615

(c) 2019 by Journal of Lake Sciences

\title{
白洋淀超微真核藻的空间分布特征及关键影响因子"
}

\author{
雷 瑾 ${ }^{1,2}$, 史小 丽 $^{2 * *}$, 张 民 $^{2}$, 李胜男 ${ }^{3}$, 陈开宁 ${ }^{2}$,杨 州 $^{1}$ \\ (1: 南京师范大学生命科学学院, 江苏省生物多样性与生物技术重点实验室, 南京 210023) \\ (2: 中国科学院南京地理与湖泊研究所湖泊与环境国家重点实验室,南京 210008) \\ (3:湖南省农业科学院,长沙 410125)
}

\begin{abstract}
摘 要: 超微真核藻个体微小、比表面积大, 具有高效的碳吸收速率, 对水体初级生产力具有重要的贡献. 目前对淡水超 微真核藻的认知还非常有限. 于 2017 年 5 月对白洋淀进行采样调查, 结合流式细胞术和高通量测序技术探究了白洋淀超 微真核藻群落结构的空间分布特征及关键环境影响因子. 结果表明, 白洋淀超微真核藻的平均丰度为 $7.59 \times 10^{4} \mathrm{cells} / \mathrm{ml}$, 且随着营养水平的升高呈现先增加后降低的变化趋势. 回归分析表明, 超微真核藻丰度在中营养水平水域主要受溶解性 总磷和 TN/TP 影响, 在富营养水域主要与盐度有关. 测序比对结果表明在纲水平上白洋淀超微真核藻主要以绿藻纲 Chlorophyceae、硅藻纲 Bacillariophyceae、中心硅藻纲 Coscinodiscophyceae、金藻纲 Chrysophyceae 为主, 不同区域差异不大. 但在操作分类单元 (Operation Taxonomy Units, OTU) 水平上, 超微真核藻群落结构在白洋淀不同营养状态湖区存在显著差 异, 中营养水域主要类群为棚列藻科 Scenedesmaceae, 近囊胞㩰属 Paraphysomona sp., 定鞭藻纲 Haptophyceae 和甲藻纲 Dinophyceae 为主, 而富营养水域主要类群为红球藻科 Haematococcaceae, 金藻纲的 Chromulinale sp. 和 Chrysophycea sp.. Bioenv 分析表明, 对超微真核藻群落组成影响最大的环境因子是溶解性总氮、溶解性总磷、TN/TP、硝态氮、溶解氧. 本研 究表明超微真核藻的群落结构存在较明显的环境异质性,对白洋淀水体富营养化状态有很好的指示.
\end{abstract}

关键词: 白洋淀; 超微真核藻; 群落结构; 环境因子; 流式细胞仪

\section{Spatial distribution characteristics of photosynthetic picoeukaryotes community structure and its impacting factors in Lake Baiyangdian}

\author{
LEI Jin ${ }^{1,2}$, SHI Xiaoli ${ }^{2 * *}$, ZHANG Min ${ }^{2}$, LI Shengnan ${ }^{3}$, CHEN Kaining ${ }^{2}$ \& YANG Zhou ${ }^{1}$ \\ (1: Jiangsu Key Laboratory for Biodiversity and Biotechnology, School of Biological Sciences, Nanjing Normal University, \\ Nanjing 210023, P.R. China) \\ (2: State Key Laboratory of Lake Science and Environment, Nanjing Institute of Geography and Limnology, Chinese Academy \\ of Sciences, Nanjing 210008, P.R.China) \\ (3: Hunan Academy of Agricultural Sciences, Changsha 410125, P.R.China)
}

Abstract: Photosynthetic picoeukaryotes (PPEs) are major primary producers in lakes, due to their small size, high surface-to-vol-
ume ratio and high carbon-specific rate of carbon uptake. However, their diversity is poorly understood in freshwater ecosystems.
PPEs community structure of Lake Baiyangdian was investigated in the May 2017 , to explore their spatial distribution features and
their relationship with environmental factors. The results based on flow cytometric analysis showed that the average abundances of
PPEs were $7.59 \times 10^{4} \mathrm{cells} / \mathrm{ml}$, and showed a peak at a certain nutrient level. Regression analysis showed that the abundance of
PPEs was affected by total dissoloved phosphorus (TDP) and TN/TP in the lake regions with mesotrophic states, but was related to
salinity in the lake regions with eutrophic states. The sequencing results indicated that PPEs were mainly dominated by Chloro-
phyceae, Bacillariophyceae, Coscinodiscophyceae and Chrysophyceae. At finer level, PPEs community structure was different in
the lake regions with two trophic states. Scenedesmaceae, Paraphysomona sp., Haptophyceae and Dinophyceae were prevalent in
mesotrophic lake regions, whereas, Haematococcaceae, Chrysophycea sp. and Chromulinale sp. were dominant in eutrophic lake

* 国家自然科学基金项目 (31670462,41877544) 资助. 2019-03-26 收稿; 2019-05-13 收修改稿. 雷瑾( 1995 ), 女, 硕士研究生;E-mail:951641944@qq.com.

** 通信作者;E-mail: xlshi@ niglas.ac.cn. 
regions. Bioenv analysis results revealed that PPEs community structure was mainly related to those environmental factors, including total dissoloved nitrogen, TDP, TN/TP, nitrate nitrogen and dissoloved oxygen. PPEs structure seemed to be a good ecological indicator for the trophic states of lakes.

Keywords: Lake Baiyangdian; photosynthetic picoeukaryotes; community structure; environmental factors; flow cytometry

超微型浮游藻类是细胞粒径 $\leqslant 3 \mu \mathrm{m}$ 的所有浮游藻类的统称, 简称超微藻 ( picophytoplankton). 超微藻广 泛分布于海洋和淡水生态系统中, 根据其细胞特性可分为超微蓝藻 ( picocyanobacteria, PCY) 和超微真核藻 (photosynthetic picoeukaryotes,PPEs). 超微藻组成复杂多样,自被发现以来,一直是海洋生态系统研究的热 点 ${ }^{[1]}$. 有关淡水生境中超微藻的研究起步相对较晚, 目前国内该方面的研究主要集中在武汉东湖、太湖、巢 湖和长江中下游等湖泊中 ${ }^{[2-3]}$, 而其它湖泊流域相关研究甚少. 超微藻个体微小、比表面积大, 因此能更高效 的获取、利用资源进行生长繁殖, 对水体的初级生产力具有重要贡献 ${ }^{[4-5]}$. 作为微食物环的一个关键起始环 节,PPEs 潜在的混合营养代谢对浮游细菌的种群具有重要调控作用 ${ }^{[6]}$. PPEs 群落组成受环境影响变化明 显, 有研究发现, PPEs 的丰度随营养条件升高而升高, 其多样性随营养水平的增加而降低, 且某些种群只存 在于特定的营养水平中, 譬如 Cyclotella atomus 是一种营养耐受的硅藻类群, 在营养水平较高的湖泊中较为 常见 ${ }^{[7]}$; 而 Chlamydomonas sp. 和 P. malhamensis 是具有异养能力的混合营养体, 在营养水平较低的条件下 具有优势 ${ }^{[8-9]}$, 因此 PPEs 的群落结构还可作为水体营养状态的判断依据.

白洋淀又名西淀, 被称为华北之肾, 位于我国华北平原海河流域中部, 是华北地区最大的内陆浅水湖 泊, 总面积 $362.8 \mathrm{~km}^{2[10]}$. 93\% 行政区隶属于保定市安新县, 保定市区是白洋淀上游最大的城市点源, 而安新 县则是白洋淀周边最大的面源. 由于生态缺水和大量工业、生活污水排放, 导致生态系统对污染的自净能力 逐渐降低, 湖水质量逐年恶化, 湖泊富营养化程度日益严峻 ${ }^{[11]}$. 白洋淀浮游藻类群落结构与水质评价的研 究结果表明, 浮游藻类密度逐年上升, 以至于多数水域处于富营养状态, 大部分水质已经恶化处于中度污染 状态 ${ }^{[12]}$. 迄今为止, 尚未有白洋淀超微型浮游藻类的报道. 本研究对白洋淀不同区域的环境因子及超微藻 群落结构进行详细调查, 分析白洋淀超微真核藻的种类组成、丰度及优势种等, 并探讨白洋淀超微真核藻群 落变化的原因. 研究结果为白洋淀湖泊生态系统的评估与诊断,生物多样性保护等方面提供理论依据.

\section{1 材料与方法}

\section{1 样品采集及水体理化参数测定}

根据白洋淀的水文条件和环境特征, 共设置 13 个采样点 (图 1), 通过 GPS 系统准确定位, 于 2017 年 5 月进行水样采集. 用有机玻璃采水器采集表层 (水面以下 $0.5 \mathrm{~m}$ )、中层和底层 (离湖底 $0.5 \mathrm{~m}$ ) 的混合湖水, 冷冻保存. 现场使用戊二醛固定 (终浓度为 $1 \%$ ) 部分水样, 液氮速冻后保存于 $-20^{\circ} \mathrm{C}$ 冰箱中, 用于后续的流 式细胞分析. 现场采用多功能水质探测仪 Yellow Spring Instruments (YSI 6600, USA) 测定水平透明度 (SD)、 水深 $(\mathrm{D})$ 、温度 $(\mathrm{T})$ 、溶解氧浓度 $(\mathrm{DO})$ 、盐度 $(\mathrm{SAL}) 、 \mathrm{pH}$ 、氧化还原电位 $(\mathrm{ORP})$ 等. 带回实验室的水样, 用于 测定水体营养盐和叶绿素 a (Chl.a). Chl. a 浓度采用丙酮法测定 ${ }^{[13-14]}$, 总氮 $(\mathrm{TN}) 、$ 硝态氮 $\left(\mathrm{NO}_{3}^{-}-\mathrm{N}\right)$ 、铵态氮 $\left(\mathrm{NH}_{4}^{+}-\mathrm{N}\right)$ 、总磷 $(\mathrm{TP})$ 、溶解性总氮 $(\mathrm{TDN})$ 和溶解性总磷 $(\mathrm{TDP})$ 浓度的测定方法参照《水和废水监测分析方 法》 ${ }^{[14]}$.

\section{2 水体营养状态评价标准}

为克服单一因子评价水平富营养化程度的片面性, 我们采用了修正后的卡尔森营养状态指数 $\left(T S I_{M}\right)$ 法 ${ }^{[15]}$ 分析了白洋淀 13 个采样点位的营养状态, $T S I_{M}$ 能够较详细地描述水体营养状况变化, 进一步提高水质 监测与评价质量. 根据水体中 $\mathrm{SD} 、 \mathrm{Chl} . \mathrm{a} 、 \mathrm{TP}$ 浓度水平计算 $T S I_{M}$ 值:

$T S I(C h l . a)=10(\ln C h l . a / \ln 2.5+2.46)$

$$
\begin{gathered}
T S I(S D)=10((2.34-1.82 \ln S D) / \ln 2.5+2.46) \\
T S I(T P)=10((1.32 \ln T P-3.28) / \ln 2.5+2.46) \\
T S I_{M}=\Sigma T S I(i) / n
\end{gathered}
$$

式中, $T S I(i)$ 代表 $T S I(S D) 、 T S I(T P) 、 T S I(C h l . a)$, 若其中某项数值缺失, 可按剩下两项值求 $T S I_{M}, n$ 代表求 
和项数.

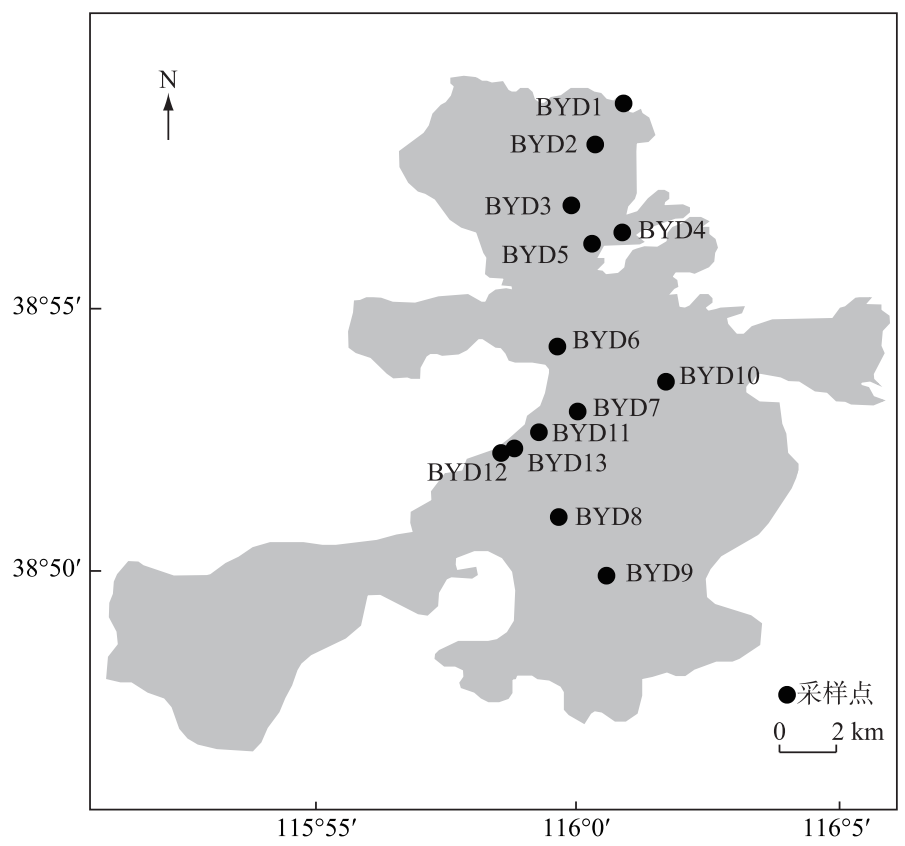

图 1 白洋淀采样点位分布

Fig. 1 Distribution of the sampling sites in Lake Baiyangdian

当 $T S I_{M}<30$ 时, 为贫营养状态; 当 $30 \leqslant T S I_{M} \leqslant 50$ 时, 为中营养状态; 当 $50<T S I_{M} \leqslant 100$ 时, 为富营养状态. 在同一营养状态下, 指数值越高, 其营养状态越高.

\section{3 流式细胞仪计数与分选}

流式细胞仪超微藻计数方法, 参照李胜男等 ${ }^{[16]}$ 研究. 分选时, 将戊二醛固定、液氮速冻保存的样品室温 解冻, 经 300 目篮绢过滤后, 根据不同类群的超微藻所含色素的自发荧光特性,结合散射光 (SSC 和 FSC) 信 号表征细胞大小, 通过流式细胞仪分选出 10 万 15 万个 PPEs 细胞, 加人 $180 \mu$ l Lysis Buffer( Tris-HCl, pH $8 ; \mathrm{EDTA}-\mathrm{Na}_{2} 2 \mathrm{mmol} / \mathrm{L}$; Triton X-100,1.2\% ), 后将样品保存于 $-20^{\circ} \mathrm{C}$, 直至 DNA 提取.

\section{4 分选样品 DNA 的提取、目标序列扩增及 Hiseq 高通量测序}

利用 DNeasy Blood \& Tissue Kit 试剂盒 ( Qiagen) 提取样品 DNA, 提取方法按照试剂盒说明书进行, 用于 后续目标片段扩增和高通量测序.

采用真核通用引物对 EK-NSF573：5'-CGCGGTAATTCCAGCTCCA-3'，Ek-NSR951：5'-TTGGYRAATGCTTTCGC-3', 对检测区域 $18 S$ rRNA V4 区进行高保真 PCR 扩增 25 个循环. 设置 3 个重复实验, 同时以标 准的细菌/细菌基因组 DNA Mix 作为阳性对照. 扩增反应程序及反应体系参考李胜男 ${ }^{[17]}$ 等研究方法. 随后 将同一样本的 3 个平行扩增产物混合, 加人等体积的核酸纯化磁珠 Agencourt AMpure XP (Beckman) 进行纯 化. 各样本添加特异性标签序列后, 对文库进行定量、混合和质量检测, 随后采用 Illumina HiSeq 高通量测序 平台, $2 \times 250 \mathrm{bp}$ 的双端测序策略对文库进行测序.

\section{5 序列分析及注释}

测序所得原始序列的质量控制和聚类过程如下: a. 使用 TrimGalore 软件去除末端质量低于 20 的序列、 去除 adapter 序列、长度小于 100 的序列; b. 使用 FLASH2 软件进行双端合并, 得到有效序列; c. 使用 mothur v. 1.39.3 软件去除序列两端引物; d. 使用 usearch 软件去除总碱基错误率大于 2 的序列以及长度小于 $100 \mathrm{bp}$ 的 序列; e. 使用 UPARSE 软件去除 singleton 序列和 Chimera 序列, 将序列按照 $98 \%$ 的相似度聚类到不同的 OTUs (Operational Taxonomic Units) 中, 共得到 373 个 OTUs, 最后根据 Silva 数据库对聚类后的 OTUs 进行注 
释. OTUs 注释完成后, 删除被归为植物 (Streptophyta) 的 OTUs. 根据 PPEs 各 OTUs 所含序列的相对比例, 我 们将 PPEs OTUs 分为优势 OTUs (所含序列数在各样品总序列数中所占的平均比例 $\geqslant 0.1 \%$ ) 和稀有 OTUs (所含序列数在各样品总序列数中所占的平均比例 $<0.1 \%$ ).

\section{6 数据分析}

采用修正后的卡尔森营养状态指数法, 计算各点位的营养指数. 采用 SPSS 16.0 软件进行相关统计分 析,采用 Origin 8.5 , ArcGIS 9.3 和 R 语言软件绘图.

\section{2 结果}

\section{1 环境因子分析}

共设置 13 个采样点位 (图 1), 白洋淀平均深度为 $2.42 \mathrm{~m}$, 采样期间平均水温在 $22^{\circ} \mathrm{C}$ 左右, 水体平均 $\mathrm{pH}$ 值为 8.26 , 偏碱性, 水体较为清澈, 透明度为 $1 \mathrm{~m}$ 左右, DO 浓度均值为 $8.80 \mathrm{mg} / \mathrm{L}$. 其它理化因子变化梯度较 大, 如 $\mathrm{TN}(0.90 \sim 3.29 \mathrm{mg} / \mathrm{L}) 、 \mathrm{TDN}(0.41 \sim 2.14 \mathrm{mg} / \mathrm{L}) 、 \mathrm{TP}(0.03 \sim 0.23 \mathrm{mg} / \mathrm{L}) 、 \mathrm{TDP}(0.004 \sim 0.1 \mathrm{mg} / \mathrm{L}) 、 \mathrm{NO}_{3}^{-}-\mathrm{N}$ $(0.11 \sim 1.25 \mathrm{mg} / \mathrm{L}) 、 \mathrm{ORP}(283.9 \sim 394.8 \mathrm{mV})$. 一般认为, 当 $\mathrm{TN}$ 浓度超过 $0.5 \mathrm{mg} / \mathrm{L} 、 \mathrm{TP}$ 浓度超过 $0.05 \mathrm{mg} / \mathrm{L}$ 时, 水体易出现富营养化 ${ }^{[18]}$, 相较而言, 白洋淀大部分区域的 TN 、TP 值都已达到发生富营养化的氮、磷浓度 条件.

表 1 白洋淀不同点位的富营养化指数

Tab.1 The trophic states of the sampling sites in Lake Baiyangdian

\begin{tabular}{cccccc}
\hline 点位 & $T S I(S D)$ & $T S I(T P)$ & $T S I($ Chl.a $)$ & $T S I_{M}$ & 营养级别 \\
\hline BYD10 & 43.45 & 42.83 & - & 43.14 & 中营养 \\
BYD9 & 50.74 & 39.93 & - & 45.34 & 中营养 \\
BYD3 & 38.46 & 45.57 & 54.41 & 46.15 & 中营养 \\
BYD4 & 42.76 & 45.84 & 50.95 & 46.52 & 中营养 \\
BYD5 & 44.93 & 45.84 & 50.95 & 47.24 & 中营养 \\
BYD1 & 36.37 & 61.28 & 44.42 & 47.36 & 中营养 \\
BYD7 & 50.14 & 50.10 & 51.82 & 50.69 & 富营养 \\
BYD8 & 58.69 & 47.31 & - & 53.00 & 富营养 \\
BYD2 & 47.36 & 59.40 & 52.32 & 53.03 & 富营养 \\
BYD11 & 58.69 & 55.24 & - & 56.97 & 富营养 \\
BYD12 & 59.32 & 58.23 & - & 58.77 & 富营养 \\
BYD13 & 63.91 & 57.30 & - & 60.60 & 富营养 \\
BYD6 & 57.22 & 67.09 & 73.87 & 66.06 & 富营养 \\
\hline
\end{tabular}

一表示数据缺失.

\section{2 营养状态评价}

各采样点位 $T S I_{M}$ 指数及营养状态如表 1 所 示,因实验操作问题, 缺失 6 个采样点 (BYD8 BYD13 点位) 的 Chl. a 数据. 13 个采样点位主要 分为中营养和富营养两个营养水平, 其中南部沿 岸区域 (BYD6 BYD8、BYD11 BYD13 点位) 及 BYD2 点位为富营养状态, 而其他点位为中营养 状态.

不同采样点位环境因子的主成分分析 ( principal components analysis, PCA) 结果表明, 中营养 与富营养水域点位分别聚成两类 (图 2), 说明 $T S I_{M}$ 法能较好区分白洋淀不同营养水平水域环 境因子变化. 其中, 中营养状态水域 SD 和 ORP 值较高, 而富营养状态水域具有较高的营养盐浓 度、DO 和 $\mathrm{pH}$ 值.

\section{3 超微真核藻丰度分布特征}

白洋淀 PPEs 的丰度范围为 $1.73 \times 10^{4} \sim 1.73 \times$ $10^{5} \mathrm{cells} / \mathrm{ml}$, 均值为 $7.59 \times 10^{4} \mathrm{cells} / \mathrm{ml}$. PPEs 丰

度最大值出现在 BYD1 点位, 最小值位于营养水平最低的 BYD10 点位. 在中营养状态水域, PPEs 丰度随营 养水平增加呈逐步上升趋势; 而在富营养状态水域, PPEs 丰度随营养水平上升逐渐降低. 总体上, 随着营养 水平的升高, PPEs 丰度呈现先增加后降低的变化趋势, 在中营养水域丰度最高 (图 3).

为进一步分析不同营养状态下, 运用多元逐步回归对 PPEs 丰度变化解释度最高的关键环境因子进行 分析, 得到中营养和富营养状态下 PPEs 丰度变化的两个模型, 结果如表 2 所示. 在中营养水平下, 对 PPEs 丰度变化解释度最高的环境因子为 TDP 和 TN/TP, 且都呈显著正相关, 解释度高达 $97.3 \%(P<0.01)$, 表明 中营养水平下, PPEs 丰度随水体中磷浓度以及氮磷比的升高而增加; 而在富营养水平中, SAL 为 PPEs 丰度 变化的关键影响因子, 解释度为 $79.5 \%, \mathrm{PPEs}$ 丰度与 SAL 呈显著正相关.

\section{4 超微真核藻多样性及群落结构变化}

对白洋淀 13 个点位的流式分选样品进行高通量测序, 共得到 29086 条高质量 PPEs18S rDNA 序列, 聚 为 73 个 OTUs ( $98 \%$ 相似度). 白洋淀水体中 PPEs 的 OTU 数在 2 22 范围内变化, Shannon 多样性指数变化 


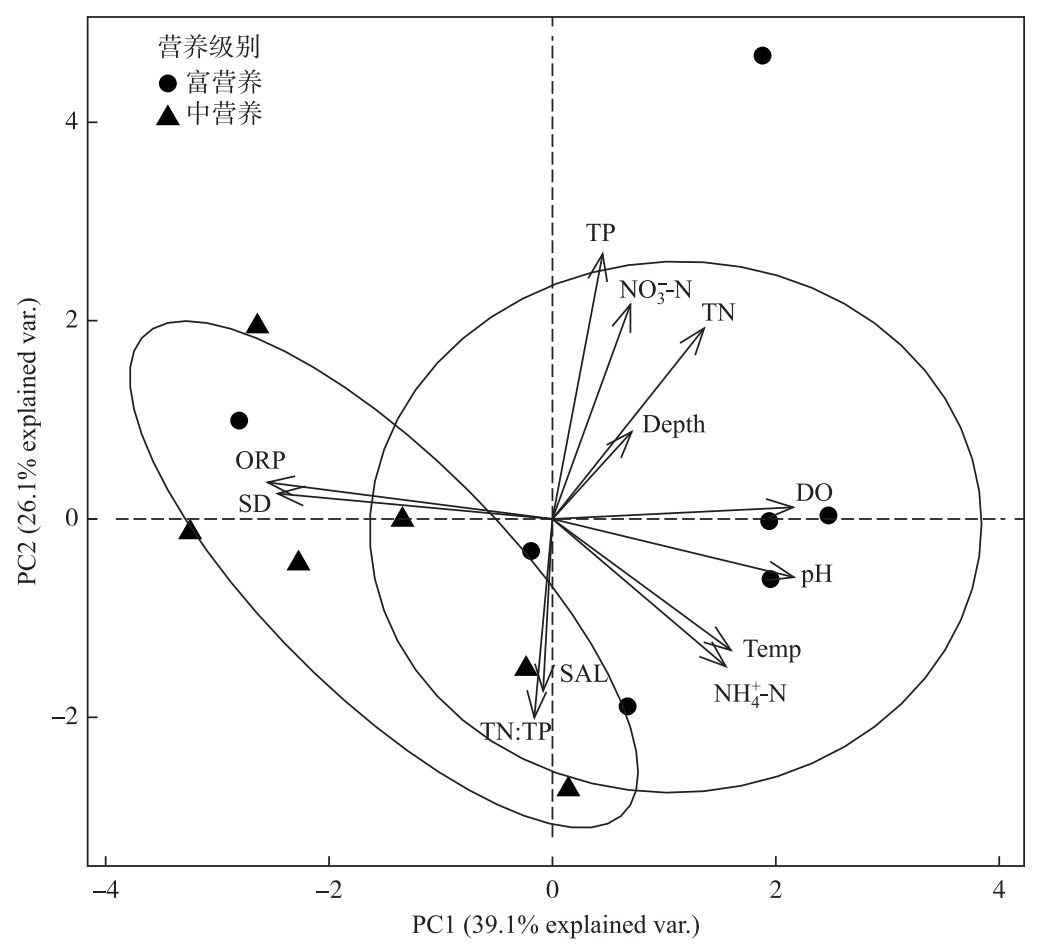

图 2 白洋淀主要环境因子 PCA 分析图

Fig.2 PCA analysis diagram of main environmental factors in Lake Baiyangdian

范围为 $0.54 \sim 2.49$, 其中 PPEs 多样性指数最低的点位 为营养水平最低的 BYD10 点位, 最高的为富营养的 BYD2 点位. PPEs 的 OTU 数在中营养和富营养水平 中无显著性差异, 但富营养水平中 PPEs 的 Shannon 多样性指数显著高于中营养水平 $(P<0.05)$ ( 图 4).

白洋淀所有 73 个 PPEs OTUs 的分类信息如表 3 所示, 其中 27 个和 19 个 OTUs 分别属于绿藻门 (Chlorophyta) 和硅藻门 (Bacillariophyta), 占总序列数 的 $81.3 \%$. 绿藻门主要以绿藻纲 Chlorophyceae (16 个 OTUs) 为主要优势类群, 此外, 还包括部分小豆藻纲 Mamiellophyceae、平藻纲 Pedinophyceae、共球藻纲 Trebouxiophyceae 和石莼纲 Ulvophyceae (共 11 个 OTUs) 序列. 硅藻门主要包括硅藻纲 (Bacillariophyceae) 和中心硅藻纲 (Coscinodiscophyceae), 其中硅藻纲序列相对较少, 但多样性更为丰富, 包括 12 个 OTUs. 除绿藻和硅藻外, 金藻纲 (Chrysophyceae) 也是白洋淀中超微藻的主要优势类群, 共检
图 3 白洋淀不同点位超微真核藻 (PPEs) 的丰度

Fig.3 PPEs abundance in different sampling sites of Lake Baiyangdian

测到 18 个金藻 OTUs, 占总序列数的 $9.64 \%$. 白洋淀中检测到的其他丰度较低的 PPEs 类群还包括甲藻纲 (Dinophyceae)、定鞭藻纲 (Haptophyceae)、硅鞭藻纲 (Dictyochophyceae)、黄群藻纲 ( Synurophyceae) 等. 虽然 绿藻纲 (16 OTUs) 和中心硅藻纲 (4 OTUs) 占总 OTUs 数仅为 $27 \%$, 但是它们贡献了超过 $50 \%$ 的序列数. 
表 2 两种营养状态下超微真核藻丰度变化的逐步回归模型

Tab.2 Stepwise regression model of PPEs abundance under two trophic states

\begin{tabular}{ccccccc}
\hline 营养水平 & Variables & $\begin{array}{c}\text { Standardized } \\
\text { Coefficients }\end{array}$ & $t$ & $P$ & \multicolumn{2}{c}{ Model } \\
\cline { 5 - 7 } 中营养 & 常量 & & -5.487 & 0.012 & 0.973 & 0.002 \\
& TDP & 1.319 & 13.408 & 0.001 & & \\
& TN/TP & 0.721 & 7.329 & 0.005 & & 0.004 \\
富营养 & 常量 & & -4.086 & 0.009 & 0.795 & \\
& SAL & 0.91 & 4.923 & 0.004 & & \\
\hline
\end{tabular}

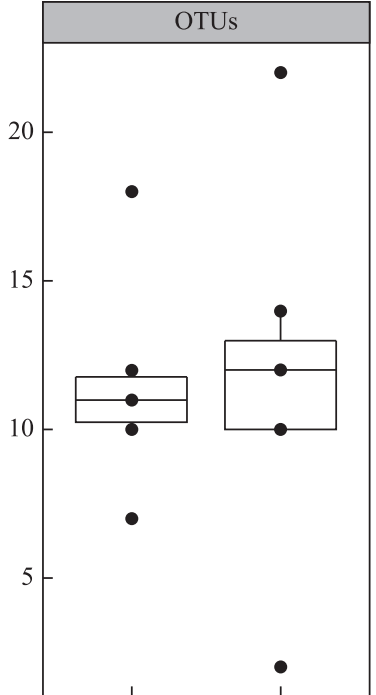

中营养富营养

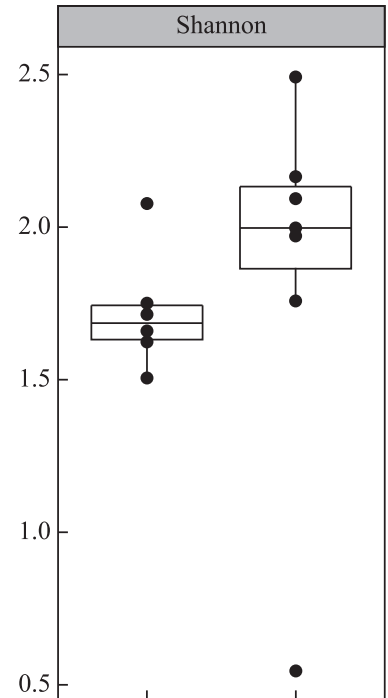

中营养富营养

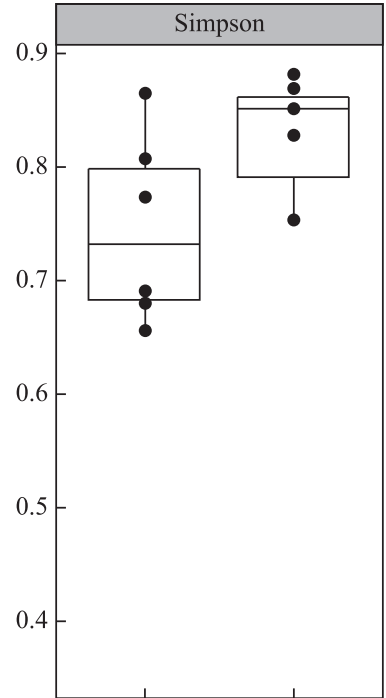

中营养富营养

图 4 白洋淀超微真核藻的 OTU 数、Simpson、Shannon 多样性指数

Fig.4 OTU numbers and diversity indexes in mesotrophic and eutrophic lake regions in Lake Baiyangdian

不同营养水平中超微真核藻的群落组成差异明显 (图 5). 定鞭藻纲的唯一 OTU253 Chrysochromulina parva 仅存在于中营养水平湖区中 $(P<0.01$, 图 6), 且在该水平上随着营养水平的升高优势度逐渐增加. 甲藻 纲 Dinophyceae 相对丰度在中营养水平湖区中显著高于富营养水平湖区 $(P<0.05)$, 其中的两个优势 OTU216 Baldinia sp. 和 OTU420 Dinophyceae sp. 丰度均远高于富营养水平点位 (图 6). 其他 PPEs 类群, 在纲水平上, 绿藻纲、金藻纲、四升藻纲 (Chlorodendrophyceae)、硅藻纲和共球藻纲( Trebouxiophyceae) 等, 相对丰度在白洋 淀富营养和中营养水平湖区中无显著性差异 (图 5), 但在更低分类水平上 (OTU 水平), 群落组成差异明显. 中营养水平湖区中, 绿藻纲主要以栅列藻科 (Scenedesmaceae) 的 OTUs 为主, 而在富营养水平中则主要以红 球藻科 (Haematococcaceae) 的 Chlorogonium 属 OTUs 为优势. 在中营养水平湖区中共检测到 9 个金藻纲 OTUs, 其中 OTU419 对应的 Paraphysomona sp. 丰度最高; 而在富营养水平中的检测到的 14 个金藻纲 OTUs, 主要以 OTU32 Chrysophycea sp. 和 OTU464 Chromulinale sp. 为优势种. 中心硅藻纲中 OTU111 Thalassiosira pseudonana 在富营养水平中丰度更高, 而 OTU98 Stephanodiscus hantzschii 则在中营养水平中相对丰度更高, 为白洋淀超微真核藻的主要优势种 (图 6).

\section{5 超微真核藻群落组成与环境因子的关系}

利用 PCA 分析了白洋淀不同营养水平水域中 PPEs 群落主要优势 OTUs 的组成变化, 结果表明前两轴 共累计解释了 $72.7 \%$ 的 PPEs 群落组成变化 (图 7). 相对于富营养水域而言, 中营养状态水域各点位间的 
表 3 白洋淀自养超微藻的分类信息

Tab.3 Taxonomic composition of OTUs retrieved from flow cytometry sorted samples collected in Lake Baiyangdian

\begin{tabular}{|c|c|c|c|c|}
\hline & 分类 & & OTU 数 & 序列数 \\
\hline \multirow[t]{5}{*}{ 绿藻门 } & 绿藻纲 & & 16 & 6971 \\
\hline & 小豆藻纲 & & 1 & 404 \\
\hline & 平藻纲 & & 2 & 199 \\
\hline & 共球藻纲 & & 7 & 729 \\
\hline & 石莼纲 & & 1 & 1801 \\
\hline \multirow[t]{7}{*}{ 不等鞭毛藻类 (AST) } & 硅藻门 & 硅藻纲 & 12 & 3627 \\
\hline & & 中心硅藻纲 & 4 & 8615 \\
\hline & & 脆杆藻纲 & 3 & 1300 \\
\hline & 金藻纲 & & 18 & 2805 \\
\hline & 硅鞭藻纲 & & 1 & 57 \\
\hline & 黄群藻纲 & & 1 & 250 \\
\hline & 环境样本 & & 1 & 380 \\
\hline 囊泡虫总门 & 甲藻纲 & & 5 & 1094 \\
\hline 定鞭藻门 & 触丝藻纲 & & 1 & 854 \\
\hline 总计 & & & 73 & 29086 \\
\hline
\end{tabular}

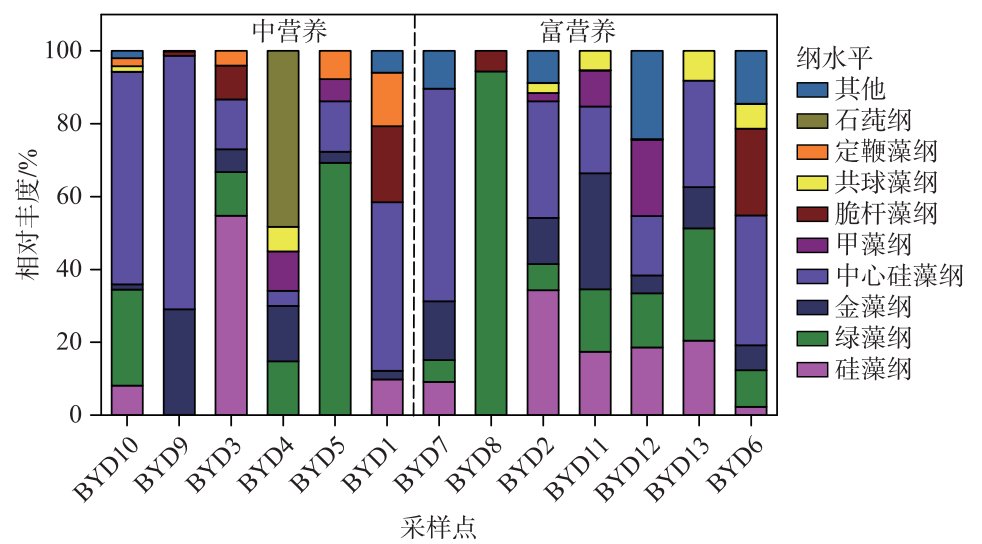

图 5 白洋淀不同营养状态湖区超微真核藻在纲水平的相对丰度

Fig.5 The main class composition of PPEs under two trophic states in Lake Baiyangdian

PPEs 群落优势 OTUs 组成更为相似, 而富营养水域各点位 PPEs 群落优势 OTUs 组成差异较大, 表明富营养 水体中 PPEs 优势物种差异较大, 群落结构更为复杂. 利用 Bioenv 函数篮选出对 PPEs 群落组成变化解释率 最高的环境因子组合, 结果表明 TDN、TDP、TN/TP、 $\mathrm{NO}_{3}^{-}-\mathrm{N} 、 \mathrm{DO} 5$ 个环境因子解释率最高, 为 $43.1 \%$.

\section{3 讨论}

白洋淀水体营养状态调查结果表明, 白洋淀水域大致呈中营养和富营养两种状态. 中营养状态的水域 主要集中在北部烧车淀和东南部大湖淀. 这些水域水体透明度高, 采样中发现了大面积沉水植被的覆盖, 主 要包括蕰草(Potamogeton crispus)、狐尾藻 (Myriophyllum verticillatum) 和黄丝草(Potamogeton maackianus). 富 营养状态的水域主要为临近村庄的湖区, 由于受到人类生活污染的影响, 富营养化程度高, 个别点位受到畜 禽养殖的影响, 污染严重, 最高富营养指数达到了 66 以上.

白洋淀不同营养状态水域 PPEs 细胞丰度及多样性差别显著, 这表明营养盐对 PPEs 的群落组成分布有 着非常重要的影响, 尤其是氮磷比. 王建等 ${ }^{[19]}$ 和 Kruk 等 ${ }^{[20]}$ 研究也发现超微藻数量随着湖泊 TN/TP 的升高 


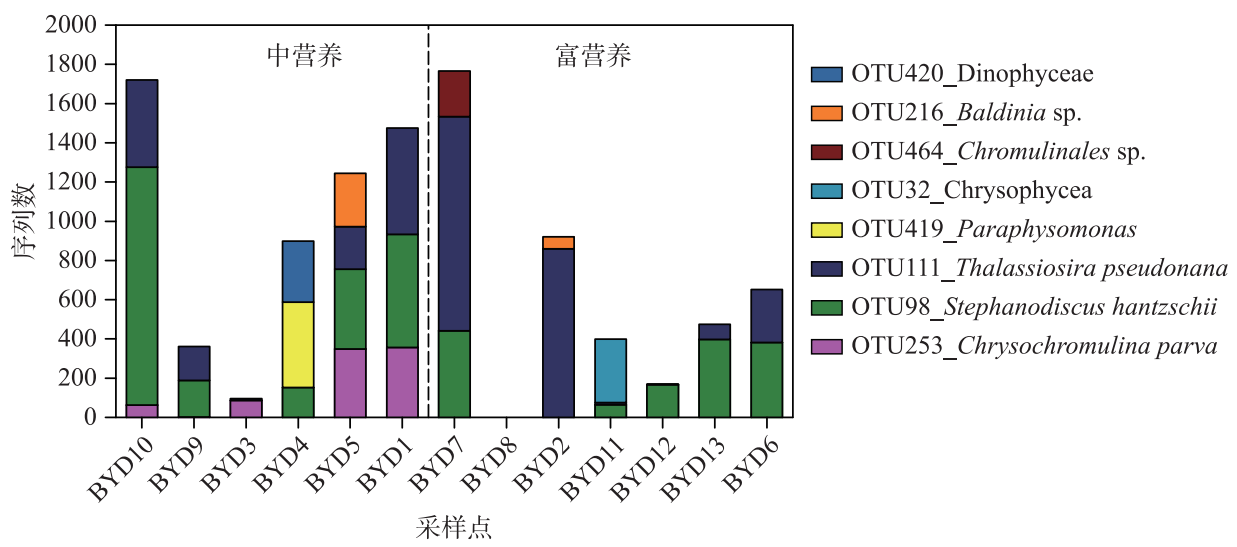

图 6 白洋淀两种营养状态湖区差异显著的 OTU 组成

Fig.6 The major OTUs composition with significant difference under two trophic states in Lake Baiyangdian

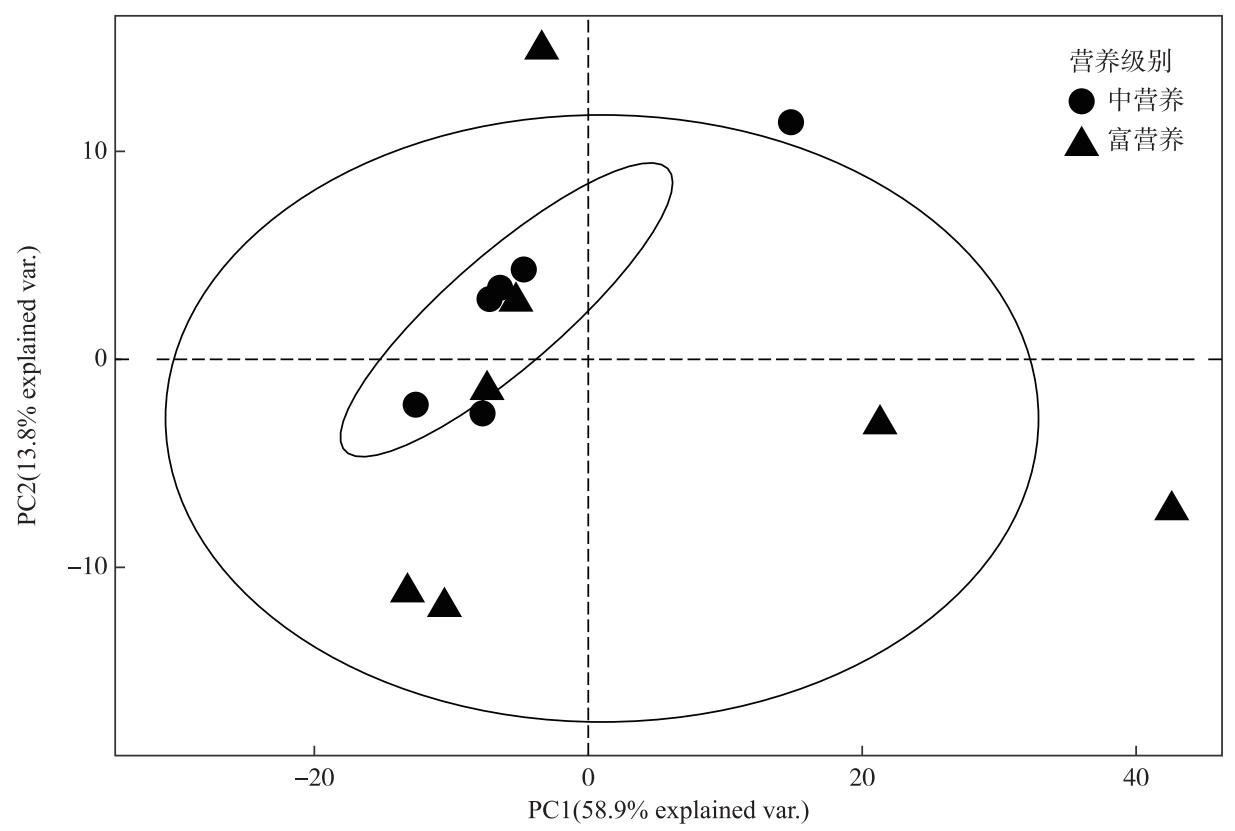

图 7 白洋淀优势 OTUs 的 PCA 分析

Fig.7 PCA analysis diagram of dominant OTUs in Lake Baiyangdian

而升高, 且氮为超微藻生长的主要限制因子. 这与本研究结果较为相似, 在白洋淀中营养水域, PPEs 丰度随 营养水平增加呈逐步上升, 且多元回归分析表明 PPEs 丰度主要跟水体中的磷浓度及 TN/TP 有关, 并在中 营养水域中随两者的升高而增加. 其中虽然 BYD9 点营养状态值低, 但 PPEs 丰度相对较高, 这可能是受其 它环境因子的影响. Lepère 等在 Bourget 湖调查中发现寄生真菌 Chytrids 作为一个重要的环境因素存在, 对 超微藻的丰度及群落演替具有调控作用 ${ }^{[21]}$. 而在富营养水域 PPEs 丰度主要与 SAL 有关, 且与 SAL 呈正相 关, 珠江口的超微型浮游藻类研究结果也发现, 且无论在夏季还是在冬季, 其正相关性始终存在, 说明盐度 是影响超微浮游藻类一个极其重要的影响因子 ${ }^{[22]}$. 盐度对浮游藻类的影响主要表现在渗透压方面 ${ }^{[23]}$.

群落物种多样性反映了群落特有的物种组成和个体密度特征. 已有研究表明, 在不同营养水平的湖区, 浮游藻类的生物量及物种的多样性也有所不同, 营养盐水平高的湖区其物种的多样性相对较低 ${ }^{[9]}$. 谢薇 
薇 ${ }^{[24]}$ 对长江中下游各湖泊的 PPEs 研究发现, 中营养湖泊 PPEs 的丰度相对较少, 但多样性却更为丰富; 而 富营养化湖泊 PPEs 虽然数量较多, 其丰度约为中营养湖泊的 4 5 倍, 但多样性较低. 这与本研究结果略有 不同, 在白洋淀富营养水域共发现 56 个 PPEs OTUs, 中营养水域 36 个, 且富营养水域 Shannon 多样性指数 显著高于中营养水域 $(P<0.05)$, 这可能是因为白洋淀富营养水域和中营养水域除营养盐指数有差别外, 还 有别的理化因子 (如 $\mathrm{pH} 、 \mathrm{ORP}$ 等因子) 也存在着显著差异, 可能对 PPEs 的多样性指数也有影响.

本研究发现白洋淀绿藻和不等鞭毛藻类丰度极高, 为优势类群, 这与先前我们在太湖、鄱阳湖、抚仙湖 的调查结果一致 ${ }^{[24-26]}$. 在 OTU 水平上, PPEs 群落结构在白洋淀不同营养状态的湖区差异明显. 绿藻纲中, 中营养水域主要以栅列藻科的 OTUs 为主, 而富营养水体中则主要以红球藻科 Chlorogonium 属的 OTUs 为优 势类群; 金藻纲中, 中营养水域主要以 OTU419 (Paraphysomona sp.) 丰度最高, 而在富营养水平水体中 OTU32 (Chrysophycea sp.) 和 OTU464 (Chromulinale sp.) 为优势种. 此外, 白洋淀中营养水域另一类丰度较高的类 群一一定鞭藻纲, 研究发现其在微型浮游生物以及超微型浮游生物的生物量中占相当大的比例 ${ }^{[27-28]}$. 定鞭 藻纲大多数属在海洋浮游生物中具有代表性, 淡水生境中也发现该类群, 目前报道有十几种, 包括 Hymenomonas roseola、Prymnesium、Chrysochromulina 等 ${ }^{[29-30]}$,Chrysochromulina 属的 C. parva 正是此次发现丰度高且普 遍存在于中营养状态水域中的物种, 说明 C. parva 更为适应低营养生态位. 另外, 中营养水平中甲藻纲相对 丰度显著高于富营养水平 $(P<0.05)$, 相关研究也表明甲藻纲以及定鞭藻纲在营养状态较低的水平中丰度较 高 ${ }^{[21,31-34]}$. 因此超微真核藻对水体的营养状态有很好的指示作用.

Bioenv 分析结果表明对白洋淀 PPEs 群落组成变化解释率最高的环境因子组合为 TDN、TDP、TN/TP、 $\mathrm{NO}_{3}^{-}-\mathrm{N} 、 \mathrm{DO}$, 说明营养盐仍是导致白洋淀 PPEs 群落组成变化最主要的影响因子, 这与大多数的研究结果一 致 ${ }^{[35-36]}$. 此外, 相关研究指出超微藻的组成和种群丰度还与风浪、捕食等环境因子有关 ${ }^{[37-40]}$. 因此, 在今后 PPEs 的研究中, 应加强对湖泊形态、气候特征、周边环境状况的调查, 并与室内模拟试验相结合, 探索 PPEs 数量及群落变化的关键影响因子.

\section{4 结论}

1) 根据营养指数, 白洋淀可以分为中营养和富营养两个营养状态湖区, 超微真核藻的丰度范围为 $1.73 \times$ $10^{4} \sim 1.73 \times 10^{5} \mathrm{cells} / \mathrm{ml}$, 在中营养水域, 丰度与营养盐浓度呈正相关, 在富营养水域, 丰度与盐度呈正相关.

2) 白洋淀超微真核藻群落结构在中营养和富营养水域存在显著差异, 中营养水域主要类群为栅列藻 科、Paraphysomona sp. 、定鞭藻纲和甲藻纲, 而富营养水域主要类群为红球藻科、Chrysophycea sp. 、 Chromulinale sp.. 因此超微真核藻能有效指示水体营养状态.

\section{5 参考文献}

[ 1 ] Szelag-Wasielewska E. Autotrophic picoplankton dynamics in a small shallow lake. Hydrobiologia, 1999, 408: 301-306.

[ 2 ] Xie WW, Gong Y, Wang ZW et al. Study on genetic diversity of eukaryotic supermicroalgae in lake by flow cytometry sorting technique. Environmental Science, 2013, 34(4): 1485-1491. [ 谢薇薇, 龚伊, 王志伟等. 利用流式细胞仪分选技 术研究湖泊真核超微藻的遗传多样性. 环境科学, 2013, 34(4) : 1485-1491.]

[ 3 ] Wang J, Lin WL. Preliminary study on the ecology of picoplankton in Donghu Lake, Wuhan. J Lake Sci, 1998, 10(4) : 71-76. DOI: 10.18307/1998.0411. [王建, 林婉莲. 武汉东湖超微藻生态学的初步研究. 湖泊科学, 1998, 10(4): 71-76.]

[ 4 ] Grob C, Hartmann M, Zubkov MV et al. Invariable biomass-specific primary production of taxonomically discrete picoeukaryote groups across the Atlantic Ocean. Environmental Microbiology, 2011, 13(12) : 3266-3274.

[ 5 ] Li WKW. Primary production of prochlorophytes, cyanobacteria, and eukaryotic ultraphytoplankton - measurements from flow cytometric sorting. Limnology and Oceanography, 1994, 39(1) : 169-175.

[ 6 ] Hartmann M, Zubkov MV, Scanlan DJ et al. In situ interactions between photosynthetic picoeukaryotes and bacterioplankton in the Atlantic Ocean: evidence for mixotrophy. Environmental Microbiology Reports, 2013, 5(6) : 835-840.

[ 7 ] Yang XD, Dong XH, Gao G et al. Relationship between surface sediment diatoms and summer water quality in shallow lakes of the middle and lower reaches of the Yangtze River. Journal of Integrative Plant Biology, 2005, 47(2) : 153-164. 
[ 8 ] Poerschmann J, Spijkerman E, Langer U. Fatty acid patterns in Chlamydomonas sp. as a marker for nutritional regimes and temperature under extremely acidic conditions. Microbial Ecology, 2004, 48(1) : 78-89.

[ 9 ] Lefranc M, Thenot A, Lepere U et al. Genetic diversity of small eukaryotes in lakes differing by their trophic status. Applied and Environmental Microbiology, 2005, 71(10) : 5935-5942.

[10] Cheng L. Analysis of water environment status of Baiyangdian Lake. Water Science and Engineering Technology, 2016, (5) : 50-52.[ 程否. 白洋淀水环境现状分析. 水科学与工程技术, 2016,(5): 50-52.]

[11] Wang Y, Liu LS, Shu YM et al. Evaluation of phytoplankton community structure and water quality in Baiyangdian Lake. J Lake Sci, 2011, 23(4) : 575-580. DOI:10.18307/2015.0501. [王瑜, 刘录三, 舒俭民等. 白洋淀浮游植物群落结构 与水质评价. 湖泊科学, $2011,23(4): 575-580$.]

[12] Jin L, Li LW, Zhou Y et al. Evaluation of phytoplankton community and water quality in three typical waters of Baiyangdian. Journal of Hebei University: Natural Science, 2017, 37(3): 329-336. [ 金否, 李林钥, 周杨等. 白洋淀三大典型水 域浮游植物群落及水质评价. 河北大学学报: 自然科学版, 2017, 37(3) : 329-336.]

[13] Songliao River Basin Water Environment Monitoring Center ed. Determination of chlorophyll in water quality by spectrophotometry. Beijing: China Water Resources and Hydropower Press, 2012: 9A4. [ 松辽流域水环境监测中心. 水质叶绿素 的测定分光光度法. 北京: 中国水利水电出版社, 2012:9A4.]

[14] Ministry of Environmental Protection of the People's Republic of China, Editorial Board of Water and Wastewater Monitoring and Analysis Methods eds. Water and Wastewater Monitoring and Analysis Methods: 4th edition. Beijing: China Environmental Science Press, 2002. [ 国家环境保护总局《水和废水监测分析方法》编委会. 水和废水监测分析方法:第 4 版. 北京: 中国环境科学出版社, 2002.]

[15] Shu JH. Discussion on evaluation method of lake eutrophication degree in China. Environmental Pollution and Prevention and Control, 1990,(5): 2-7. [舒金华. 我国湖泊富营养化程度评价方法的探讨. 环境污染与防治, 1990, (5): 2-7.]

[16] Li SN, Wang XJ, Zhou J et al. Methods for counting microplankton by flow cytometry. J Lake Sci, 2015, 27 (5) : 757 766. DOI: $10.18307 / 2015.0501$. [李胜男, 王秀娟, 周建等. 利用流式细胞仪计数微型浮游生物的方法. 湖泊科学, $2015,27(5): 757-766$.

[17] Li SN, Shi XL, Xie WW et al. Genetic diversity of photosynthetic picoeukaryotes in the middle and lower reaches of the Yangtze River. Environmental Science, 2013, 34(9): 3416-3422. [李胜男, 史小丽, 谢薇薇等. 长江中下游湖泊超微 型真核藻类遗传多样性研究. 环境科学, 2013, 34(9) : 3416-3422.]

[18] Melack JM, Kilham P, Fisher TR. Responses of phytoplankton to experimental fertilization with ammonium and phosphate in an african soda lake. Oecologia, 1982, 52(3) : 321-326.

[19] Wang J, Xie P, Gao CDZ. The horizontal distribution of different types of ultramicroalgae and its environmental significance. Kunming: The Abstract Collection of the Eleventh Academic Symposium of the Chinese Algae Society, 2001. [王 建, 谢平, 高村典子. 超微藻不同类型水体分布状况及其环境意义. 昆明: 中国藻类学会第十一次学术讨论 会, 2001.]

[20] Kruk M, Kobos J, Nawrocka L et al. Positive and negative feedback loops in nutrient phytoplankton interactions related to climate dynamics factors in a shallow temperate estuary (Vistula Lagoon, southern Baltic). Journal of Marine Systems, 2018, 180: 49-58.

[21] Lepere C, Domaizon I, Debroas D. Unexpected importance of potential parasites in the composition of the freshwater smalleukaryote community. Applied and Environmental Microbiology, 2008, 74(10) : 2940-2949.

[22] Zhang X, Huang XP, Shi Z et al. Spatial and temporal distribution of ultraplankton in the pearl river estuary and its relationship with environmental factors. Acta Ecologica Sinica, 2013, 33(7) : 2200-2211. [张霞, 黄小平, 施震等. 珠江口 超微型浮游植物时空分布及其与环境因子的关系. 生态学报, 2013, 33(7): 2200-2211.]

[23] Chen ZF. Study on the culture of Chaetoceros sinensis-I. Salinity, the effect of phosphate and nitrate concentration on growth and reproduction. Chinese Journal of Oceanography, 1982, (5) : 608-616. [陈贞奋. 牟氏角毛藻的培养研究一 I . 盐度、磷酸盐和硝酸盐浓度对生长繁殖的作用. 海洋学报:中文版, 1982,(5):608-616.]

[24] Xie WW. Genetic diversity of eukaryotic ultramicroalgae in freshwater lakes[Dissertation]. Nanjing: Nanjing Agricultural University, 2013. [谢薇薇. 淡水湖泊真核超微藻遗传多样性研究 [学位论文]. 南京: 南京农业大学, 2013.]

[25] Li SN. Community structure characteristics of ultra-low phytoplankton and its response to elevated $\mathrm{CO}_{2}$ in eutrophic lakes 
[Dissertation]. Nanjing: Nanjing Institute of Geography and Limnology, Chinese Academy of Sciences, 2017. [李胜男. 富营养化湖泊超微型浮游藻类群落结构特征及其对 $\mathrm{CO}_{2}$ 升高的响应 [学位论文]. 南京: 中国科学院南京地理与 湖泊研究所, 2017.]

[26] Zhou J. Temporal and spatial distribution characteristics of ultra-low phytoplankton in Poyang Lake [Dissertation]. Nanjing: Nanjing Institute of Geography and Limnology, Chinese Academy of Sciences, 2016. [ 周建. 鄱阳湖超微型浮游藻 类时空分布特征研究 [ 学位论文]. 南京: 中国科学院南京地理与湖泊研究所, 2016.]

[27] Masquelier S, Foulon E, Jouenne F et al. Distribution of eukaryotic plankton in the English Channel and the North Sea in summer. Journal of Sea Research, 2011, 66(2) : 111-122.

[28] Thomsen HA. Haptophytes as components of marine phytoplankton. The Haptophyte Algae, 1994, 51(1): 187-208.

[29] Nicholls KH ed. Haptophyte algae. Freshwater algae of North America. Oxford: Academic Press, 2015: 587-605.

[30] Manton I, Peterfi L. Observations on the tine structure of coccoliths, scales and the protoplast of a freshwater coccolithophorid, Hymenomonas roseola Stein, with supplementary observations on the protoplast of Cricosphaera carterae. Proceedings of the Royal Society of London Series B Biological Sciences, 1969, 172(1026) : 1-15.

[31] Lepere C, Domaizon I, Hugoni M et al. Diversity and dynamics of active small microbial eukaryotes in the anoxic zone of a freshwater Meromictic Lake(Pavin, France). Frontiers in Microbiology, 2016, 130(7) : 1-11.

[32] Lepere C, Boucher D, Jardillier L et al. Succession and regulation factors of small eukaryote community composition in a lacustrine ecosystem(Lake pavin). Applied and Environmental Microbiology, 2006, 72(4) : 2971-2981.

[33 ] Kirkham AR, Lepere C, Jardillier LE et al. A global perspective on marine photosynthetic picoeukaryote community structure. Isme Journal, 2013, 7(5): 922-936.

[34] Bouman HA, Ulloa O, Barlow R et al. Water-column stratification governs the community structure of subtropical marine picophytoplankton. Environmental Microbiology Reports, 2011, 3(4) : 473-482.

[35] Winder M. Photosynthetic picoplankton dynamics in Lake Tahoe: temporal and spatial niche partitioning among prokaryotic and eukaryotic cells. Journal of Plankton Research, 2009, 31(11) : 1307-1320.

[36] Luis Otero-Ferrer J, Cermeno P, Bode A et al. Factors controlling the community structure of picoplankton in contrasting marine environments. Biogeosciences, 2018, 15(20): 6199-6220.

[37] Jeppesen E, Sondergaard M, Sortkjaer O et al. interactions between phytoplankton, zooplankton and fish in a shallow, hypertrophic lake-A study of phytoplankton collapses in Lake Sobygard, Denmark. Hydrobiologia, 1990, 191 (11): 149-164.

[38 Collado-Fabbri S, Vaulot D, Ulloa O. Structure and seasonal dynamics of the eukaryotic picophytoplankton community in a wind-driven coastal upwelling ecosystem. Limnology and Oceanography, 2011, 56( 6) : 2334-2346.

[39] Chang J, Lin KH, Chen KM et al. Synechococcus growth and mortality rates in the East China Sea: range of variations and correlation with environmental factors. Deep-Sea Research Part I-Topical Studies in Oceanography, 2003, 50 (67): 1265-1278.

[40] Rajaneesh KM, Mitbavkar S, Anil AC. Influence of short-term hydrographic variations during the north-east monsoon on picophytoplankton community structure in the eastern Arabian Sea. Continental Shelf Research, 2017, 146: 28-36. 